\title{
Sympathetic Nervous System Activity in Patients with Metabolic Syndrome, Type 2 Diabetes Mellitus and Chronic Kidney Disease. Role of Renalase and Alpha Amylase
}

\author{
Hernández LE ${ }^{1}$, Hernández GP², Sánchez DCV \\ García $\mathrm{AG}^{3}$ and Aguilar $\mathbf{C A}^{2,4 *}$ \\ ${ }^{1}$ Family Medicine Unit No. 80, Mexican Institute of Social \\ Security (IMSS) Morelia, Michoacán, México \\ ${ }^{2}$ Faculty of Medical and Biological Sciences "Dr. Ignacio \\ Chávez", Michoacán University of San Nicolás de Hidalgo. \\ Morelia, Michoacán, México \\ ${ }^{3}$ Division of Clinic Research. Biomedical Research Center \\ of Michoacán, IMSS. Morelia, Michoacán, México \\ ${ }^{4}$ Medical Research Assistant Coordination in Health of \\ the IMSS, Morelia, Michoacán, México \\ *Correspondling author: Cleto Alvarez Aguilar, \\ Medical Research Assistant Coordination in Health of the \\ IMSS, Morelia, Michoacán, México
}

Received: May 01, 2021; Accepted: May 20, 2021; Published: May 27, 2021

\begin{abstract}
Aim: To evaluate serum renalase and salivary alpha amylase concentrations and their relationship with plasma catecholamine levels in patients with Metabolic Syndrome (MS), Type 2 Diabetes Mellitus (T2DM), and End-Stage Renal Disease (ESRD).

Method: In cross-sectional study 163 patients were enrolled; 43 patients with MS, 93 withT2DM, 13 with ESRD, and 14 healthy subjects (control group). All patients had their ascription to the UMAA/UMF No. 75, in Morelia, Michoacan, Mexico. Glucose, creatinine, cholesterol, triglycerides, HDL, and renalase were measurement in serum, and Dopamine (DA), Epinephrine (E) and Norepinephrine (NE) in plasma. An aliquot of saliva was collected for alpha amylase determination.
\end{abstract}

Results: High plasma concentrations of DA, E and NE $(p<0.0001)$ was founded in T2DM and ESRD patients. Renalase was lower in ESRD compared to MS and T2DM patients $(p<0.0001)$. High concentrations of alpha amylase were found in MS, T2DM, and ESRD patients in comparison with control group $(p<0.0001)$. Catecholamines correlated positively with alpha amylase and diabetes evolution.

Conclusion: Sympathetic hyperactivity in MS, T2DM and ESRD patients was founded. Renalase could be proposed as biomarker of renal function and salivary alpha amylase as sympathetic hyperactivity. Additional studies are required to evaluate the pathophysiological mechanisms involved of SNS in CKD development.

Keywords: Renalase; Alpha amylase; Sympathetic activity; Metabolic syndrome; Type 2 diabetes mellitus; Chronic kidney disease

\section{Introduction}

Metabolic Syndrome (MS) is defined as a cluster of metabolic abnormalities that increase the risk for the development of Cardiovascular Diseases (CVD) and diabetes, including abdominal obesity, elevated plasma glucose and triglycerides, reduction in HighDensity Lipoproteins (HDL) and high blood pressure levels [1]. MS is becoming one of the main public health problems of the $21^{\text {st }}$ century, as it is strongly associated with a 5 -fold increase in the prevalence of Type 2 Diabetes Mellitus (T2DM) and a 2-3-fold increase in CVD $[2,3]$.

The American Diabetes Association defines T2DM as a metabolic disorder characterized by chronic hyperglycemia related to disturbances in the carbohydrate, fat and protein metabolism, that translate into defects in the secretion and action of insulin [4]. Epidemiological data show that T2DM is a risk factor for CVD morbidity and mortality [5].

The National Kidney Foundation (NKF), Kidney Diseases
Outcomes Quality Initiative (KDOQI) (NKF-KDOQI) in its clinical practice guidelines defines Chronic Kidney Disease (CKD) as kidney damage or Glomerular Filtration Rate (GFR) $\leq 60 \mathrm{ml} / \mathrm{min} / 1.73 \mathrm{~m} 2 \mathrm{SC}$ that lasts for 3 or more months, regardless of the cause [6]. Diabetes [7] and Hypertension [8] are responsible for up to two thirds of CKD cases, although there are other risk factors such as age, family history, race, low educational and socioeconomic levels, other chronic systemic diseases, and drug toxicity [9].

Renalase is produced and secreted mainly by glomerular and tubular cells in the kidney. One function of renalase is to regulate blood pressure and cardiovascular function through circulating catecholamine degradation [10]. Renalase is also expressed in heart, musculoskeletal tissue, and small intestine [11,12] and its concentration is regulated by renal function, renal perfusion, and catecholamine concentrations [13]. Renalase has been referred as a new candidate for DM2diagnosis [14] and as a therapeutic target in the prevention of cardiorenal syndrome, as it was suggested by Yin et al. [15] inan experimental model of nephrectomizedrats, in 
which renalase absence protected against renal injury and cardiac remodeling.

Alpha Amylase is an endoamylaserelated to carbohydrate digestion that is mainly expressed in pancreas and salivary glands. Amylase catalyzes the hydrolysis of $\alpha, 1-4$ glycosidic bonds in the inner part of glycogen and starch chains, ultimately producing monosaccharides [16]. Human studies provided direct evidence of alpha amylase sensitivity in adrenergic activity, specifically related to psychological stress, mediated through beta receptors [17]. Recently, alpha amylase has been proposed as a non-invasive biomarker of chronic psychosocial stress, in which its activity is found elevated [18].

Sympathetic nerve activity is increased in CKD patients as a result of increased vascular resistance and blood pressure, which in turn leads to an increase in circulating catecholamine levels [Dopamine (DA), Epinephrine (E) and Norepinephrine (NE)] due to a reduction in glomerular filtration [19]. However, there is controversy in relation toplasma levels of catecholamines in patients with T2DM and CKD and their possible implications in the pathogenesis and complications of this disease [20]. Therefore, the objective of this study was to evaluate serum renalase and salivary alpha amylase concentrations and their relationship with plasma catecholamine levels in patients with MS, T2DM, and End-Stage Chronic Disease (ESRD) secondary to diabetes.

\section{Material and Methods}

A total of 163 patients were enrolled in a prospective, crosssectional study; from them, 43 patients with MS diagnosis (MS), 93 patients with T2DM, 13 with ESRD and 14 healthy subjects as control group, recruited from Outpatient Medical Unit (UMAA)/Family Medicine Unit No. 75 (UMF No. 75) (UMAA/UMF No. 75), of the Instituto Mexicano of Seguro Social (IMSS) in Morelia Michoacán, Mexico.

The inclusion criteria for all groups were: age $\geq 20$ years, both genders, without inflammatory, infectious pathology or bleeding in the oral cavity. For T2DMgroup a diagnosis older than 6 months was considered, according to the American Diabetes Association criteria [21]. Finally, for ESRD patients in replacement treatment of renal function with hemodialysis, were included. All subjects were informed of the purpose of the study before giving their consent. MS diagnosis was made according to International Diabetes Federation (IDF) criteria, estimating central obesity by an abdominal circumference $\geq 94 \mathrm{~cm}$ in men, $\geq 80 \mathrm{~cm}$ in women, plus one or two of the following risk factors: blood pressure $\geq 130 / 85 \mathrm{mmHg}$, triglycerides $\geq 150 \mathrm{mg} /$ $\mathrm{dL}, \mathrm{HDL}-\mathrm{C}<40 \mathrm{mg} / \mathrm{dL}$ in $\mathrm{men},<50 \mathrm{mg} / \mathrm{dL}$ in women and fasting glucose between 100 to $125 \mathrm{mg} / \mathrm{dL}$, as oral glucose tolerance curve is suggested but not essential to MS diagnosis [22].

Ablood sample of approximately $12 \mathrm{ml}$ was taken from al participants. In control group, MS and T2DM, sample was taken from antecubital vein of left arm in a supine position, after 10 hours of fasting. In ESRD group, blood was taken fromarterial line before hemodialysis. Saliva sample was collected in 10 hours fasting, without eating, drinking, chewing gum, or cleaning their mouth for at least 60 minutes prior to sample. Blood samples were centrifuged at 3,500 rpm for 10 minutes in a refrigerated centrifuge and serum/ plasma obtained was stored at $-70^{\circ} \mathrm{C}$ (SANYO Biomedical Freezer Mod. Allegra X-22) until processing. Serum was used for glucose, creatinine, total cholesterol, triglycerides and HDL-c determination (Automated Clinical Chemistry equipment, Vitros 5.1 FSSANYO, Series 34001004). Renalase was assessed by ELISA commercial kit (BioAssay ${ }^{\mathrm{TM}}$ ELISA Kit Human). Plasma catecholamines (DA, E and NE) were measured by HPLC (WatersTM Mod. 2487, Milford, USA).Whereas salivary Alpha amylase was determined by ELISA commercial kit (USBiological ${ }^{\mathrm{TM}}$ Amylase Alpha Bioassay ELISA Kit Human), with a detection range of $0-400 \mathrm{U} / \mathrm{mL}$. The eGFR was estimated using the Chronic Kidney Epidemiology Collaboration (CKD-EPI) equation [23].

This study protocol was approved by Local Research and Health Research Ethics Committee \#1602 of IMSS in Morelia, Michoacán, México.

\section{Statistical analysis}

Results are shown as mean \pm standard deviation. The normality of the variable distribution was verified using the Kolmogorov-Smirnov test. Mean differences were evaluated with Kruskal-Wallis test and U de Mann Whitney. Spearman's correlation coefficient was used for the assessment of correlation between variables. All variables were analyzed in statistical package SPSS.V21 for PC. Statistical significance was considered $\mathrm{p}<0.05$.

\section{Results}

Table 1 resumes the results of clinical and biochemical variables in studied population. BMI, SBP, DBP, MAP, and eGFR in MS, T2DM and ESRD were statistically different compared to control group $(\mathrm{p}<0.01)$. ESRD had the highest serum creatinine concentrations. Also, a decrease in eGFR was observed in DM2 patients in relation to control group and MS $(\mathrm{p}<0.01)$. In SNS activity parameters, higher plasma concentrations of DA $(\mathrm{p}<0.01), \mathrm{E}(\mathrm{p}<0.05)$, and NE $(\mathrm{p}<0.001)$ was found in the patients with ESRD and T2DM compared to control group.

Interestingly, renalase concentrations were lower in ESRD compared to T2DM and MS ( $<<0.0001)$ while higher concentrations of salivary alpha amylase were found in MS, T2DM, and ESRD patients compared with control group $(\mathrm{p}<0.0001)$ (Figure 1).

Table 2 show the univariate analysis of serum renalase and salivary alpha amylase with other variables analyzed. We found an inverse correlation between serum renalase, blood pressure, and diabetes evolution. While positive correlation was found with serum glucose, and GFRe. Moreover, salivary alpha amylase had a negative correlation with eGFR and a positive correlation with BP, serum glucose, and plasma DA, E and NE.

Figure 2 report important correlations between diabetes evolution and MBP $(r=0.351 ; \mathrm{p}<0.0001), \mathrm{DA}(\mathrm{r}=0.296 \mathrm{p}=0.0002), \mathrm{E}(\mathrm{r}=0.474$, $\mathrm{p}=<0.0001), \mathrm{NE}(\mathrm{r}=0.443, \mathrm{p}<0.0001)$, salivary alpha amylase $(\mathrm{r}=0.256$, $\mathrm{p}=0.009)$ and eGFR $(\mathrm{r}=-0.604, \mathrm{p}<0.0001)$. Additionally, correlations between eGFR and DA $(r=-0.629, \mathrm{p}<0.0001), \mathrm{E}(\mathrm{r}=-0.662, \mathrm{p}<0.0001)$, $\mathrm{NE}(\mathrm{r}=-0.635, \mathrm{p}<0.0001)$ and $\mathrm{MBP}(\mathrm{r}=-0.480, \mathrm{p}<0.0001)$ are represented in Figure 3.

\section{Discussion}

SNS hyperactivity has important effects on several diseases 
Table 1: Clinical, anthropometric and biochemical variables of the studied population.

\begin{tabular}{|c|c|c|c|c|}
\hline Variables & $\begin{array}{c}\text { Control } \\
\text { Group } \\
n=14\end{array}$ & $\begin{array}{c}\text { MS Group } \\
n=43\end{array}$ & $\begin{array}{c}\text { DM2 Group } \\
n=93\end{array}$ & $\begin{array}{c}\text { ESRD } \\
\text { Group } \\
n=13\end{array}$ \\
\hline Gender (M/F) & $6 / 8$ & $17 / 26$ & $31 / 62$ & $7 / 6$ \\
\hline Age (years) & $49 \pm 11$ & $50 \pm 10$ & $59 \pm 10^{*}$ & $50 \pm 17$ \\
\hline BMI $\left(\mathrm{kg} / \mathrm{m}^{2}\right)$ & $22.8 \pm 1.9$ & $29.8 \pm 3.8^{*}$ & $29.6 \pm 4.4^{*}$ & $27.7 \pm 5.2^{* * *}$ \\
\hline BPS (mm/hG & $113 \pm 6$ & $129 \pm 15^{* *}$ & $140 \pm 19^{*}$ & $166 \pm 13^{*}$ \\
\hline BPD (mm/Hg) & $75 \pm 6$ & $84 \pm 11^{* *}$ & $86 \pm 11^{* *}$ & $101 \pm 7^{\star}$ \\
\hline MBP (mm/Hg) & $88 \pm 4$ & $98 \pm 10^{* * *}$ & $104 \pm 11^{*}$ & $117 \pm 6^{*}$ \\
\hline $\begin{array}{l}\text { Diabetes evolution } \\
\text { (years) }\end{array}$ & ------ & ------ & $7 \pm 6$ & $20 \pm 3^{\delta}$ \\
\hline Glucose (mg/dL) & $86.2 \pm 8.3$ & $104.0 \pm 9.6^{* \star \star}$ & $135.7 \pm 45.3^{\star}$ & $97.5 \pm 21.8$ \\
\hline $\begin{array}{l}\text { eGFR }\left(\mathrm{ml} / \mathrm{min} / \mathrm{m}^{2}\right. \\
\text { BS) }\end{array}$ & $104.8 \pm 105.9$ & $87.6 \pm 15.9^{* *}$ & $77.6 \pm 18.1^{\star}$ & $5.6 \pm 1.5^{\star}$ \\
\hline TC (mg/dL) & $165.7 \pm 32.8$ & $175.2 \pm 34.2$ & $167.1 \pm 42.4$ & $146.7 \pm 31.2$ \\
\hline $\mathrm{TG}(\mathrm{mg} / \mathrm{dL})$ & $118.7 \pm 51.8$ & $183.2 \pm 76.7^{4+*}$ & $171.4 \pm 76.7^{*+*}$ & $167.3 \pm 39.2^{* * *}$ \\
\hline $\mathrm{c}-\mathrm{HDL}(\mathrm{mg} / \mathrm{dL})$ & $47.8 \pm 10.9$ & $37.8 \pm 7.1^{* * *}$ & $40.1 \pm 11.3^{*+*+}$ & $38.1 \pm 8.7$ \\
\hline Dopamine (pg/mL) & $11.4 \pm 2.6$ & $21.1 \pm 10.6$ & $25.7 \pm 15.3^{*+}$ & $61.8 \pm 14.7^{\star}$ \\
\hline Epinephrine $(\mathrm{pg} / \mathrm{mL})$ & $14.2 \pm 3.3$ & $23.1 \pm 14.6$ & $33.1 \pm 28.2^{\text {tatk }}$ & $105.9 \pm 32.6^{*}$ \\
\hline $\mathrm{NE}(\mathrm{pg} / \mathrm{mL})$ & $40.2 \pm 9.1$ & $150.4 \pm 88.4^{* *}$ & $198.4 \pm 111.2^{*}$ & $438.4 \pm 114.6^{*}$ \\
\hline
\end{tabular}

Results are expressed in media $\pm S D$; MS Group: Metabolic Syndrome Group; DM2 Group: Diabetes mellitus 2 Group; ESRD Group: End-stage renal disease BMI: Body Mass Index; SBP: Systolic Blood Pressure; DBP: Diastolic Blood Pressure; MBP: Mean blood pressure (DBP+1/3 of difference SBP-DBP); eGFR= Estimated Glomerular Filtration Rate; TC=Total Cholesterol; TG: Triglycerides; c-HDL: High Density Lipoprotein; NE= Norepinephrine; " $p<0.0001 ;{ }^{* *} p<0.01$ ${ }^{*} \mathrm{p}<0.05$; Control group vs MS, T2DM and ESRD group; ${ }^{\circ} \mathrm{p}<0.0001$ T2DM vs ESRD group.

including hypertension [24], obesity [25], MS [26] and T2DM [27]. The pathogenesis of T2DM is not fully established and involves complex adaptations to high food intakes and chronic inactivity [28]. SNS has important implications in the regulation of the energy balance in short and long term and, therefore, it has been related to T2DMpathogenesis [29]. However, there is still in debate if SNS hyperactivity could have an important role in T2DMdevelopment, or if, on the contrary, hyperglycemia and chronic hyperinsulinemia lead to alteration in SNS function.

On the other hand, renalase has recently been described as a catecholamine metabolizing hormone [30]. While salivary alpha amylase activity has been measured as a marker of SNS activity $[31,32]$.

In our study, we found an increase in plasma concentrations of dopamine, epinephrine, norepinephrine and salivary alpha amylase in patients with T2DM and ESRD; similarly, increased serum concentration of renalase was observed in patients with MS and T2DM, while in patients with ESRD renalase concentration was similar to control subjects. These results concur with reports of SNS activity in subjects with hypertension [33], obesity [34] and diabetes [35]. In this regard, SNS hyperactivity has been described in patients with CKD $[36,37]$ and it supports why CKD is considered a risk factor for CVD development [38].

We found higher values of serum renalase in MS and T2DM patients, but only a non-significant increase in ESRD patients, these results, contrast with other reports where high serum concentrations
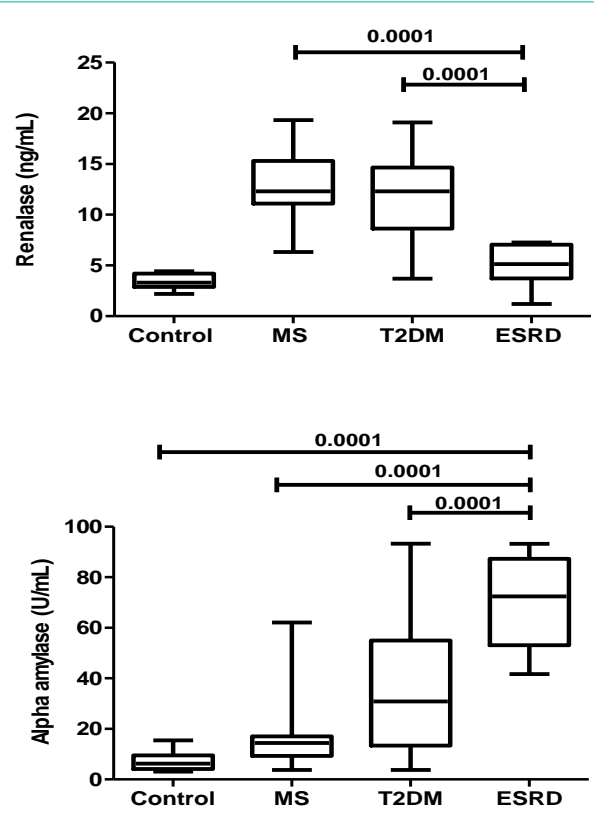

Figure 1: Renalase and alpha amylase concentration in study groups.

Table 2: Correlation between renalase, alpha amylase, clinical and biochemical variables of the studied population.

\begin{tabular}{|c|c|c|c|c|}
\hline \multirow{2}{*}{ Variables } & \multicolumn{2}{|c|}{ Renalase } & \multicolumn{2}{|c|}{ Salivary alpha amylase } \\
\hline & Spearman test & $P$ & Spearman test & $P$ \\
\hline Age (yr) & 0.104 & 0.391 & 0.104 & 0.197 \\
\hline $\mathrm{BMI}\left(\mathrm{m}^{2}\right)$ & 0.3 & $<0.0001$ & 0.136 & 0.09 \\
\hline SBP (mm/hg) & -0.193 & 0.014 & 0.499 & $<0.0001$ \\
\hline DBP (mm/hg) & -0.238 & 0.002 & 0.472 & $<0.0001$ \\
\hline MBP (mm/hg) & -0.22 & 0.005 & 0.488 & $<0.0001$ \\
\hline $\begin{array}{l}\text { Diabetes evolution } \\
\text { (years) }\end{array}$ & -0.328 & $<0.001$ & 0.19 & 0.054 \\
\hline Glucose (mg/dL) & 0.216 & 0.006 & 0.241 & 0.002 \\
\hline $\begin{array}{l}\text { Total Cholesterol } \\
(\mathrm{mg} / \mathrm{dL})\end{array}$ & 0.092 & 0.242 & -0.173 & 0.12 \\
\hline Triglycerides (mg/dL) & 0.166 & 0.035 & 0.097 & 0.227 \\
\hline eGFR $\left(\mathrm{ml} / \mathrm{min} / \mathrm{m}^{2} \mathrm{SC}\right)$ & 0.188 & 0.016 & -0.422 & $<0.0001$ \\
\hline Dopamine pg/mL) & -0.095 & 0.229 & 0.574 & $<0.0001$ \\
\hline Epinephrine $(\mathrm{pg}(\mathrm{mL})$ & -0.151 & 0.054 & 0.614 & $<0.0001$ \\
\hline Norepinephrine (pg/mL) & -0.153 & 0.051 & 0.684 & $<0.0001$ \\
\hline
\end{tabular}

BMI: Body Mass Index; SBP: Systolic Blood Pressure; DBP: Diastolic Blood Pressure; MBP: Mean blood pressure (DBP+1/3 of difference SBP-DBP); eGFR: Estimated Glomerular Filtration Rate.

of renalase were found in ESRD patients in hemodialysis with Residual Renal Function (RRF) [39]. Which leads us to highlight the importance of preserving RRF in CKD patients undergoing renal function replacement therapy, due to relevance of kidney endocrine function in SNS homeostasis [40].

In fact, control group, serum renalase differed from values reported for different ethnicities. To our knowledge, this is the first report of serum renalase in Mexican population, in which, the mestizo population comprises approximately $80 \%$, while $20 \%$ corresponds to Mexican-indians and European immigrants [41]. 


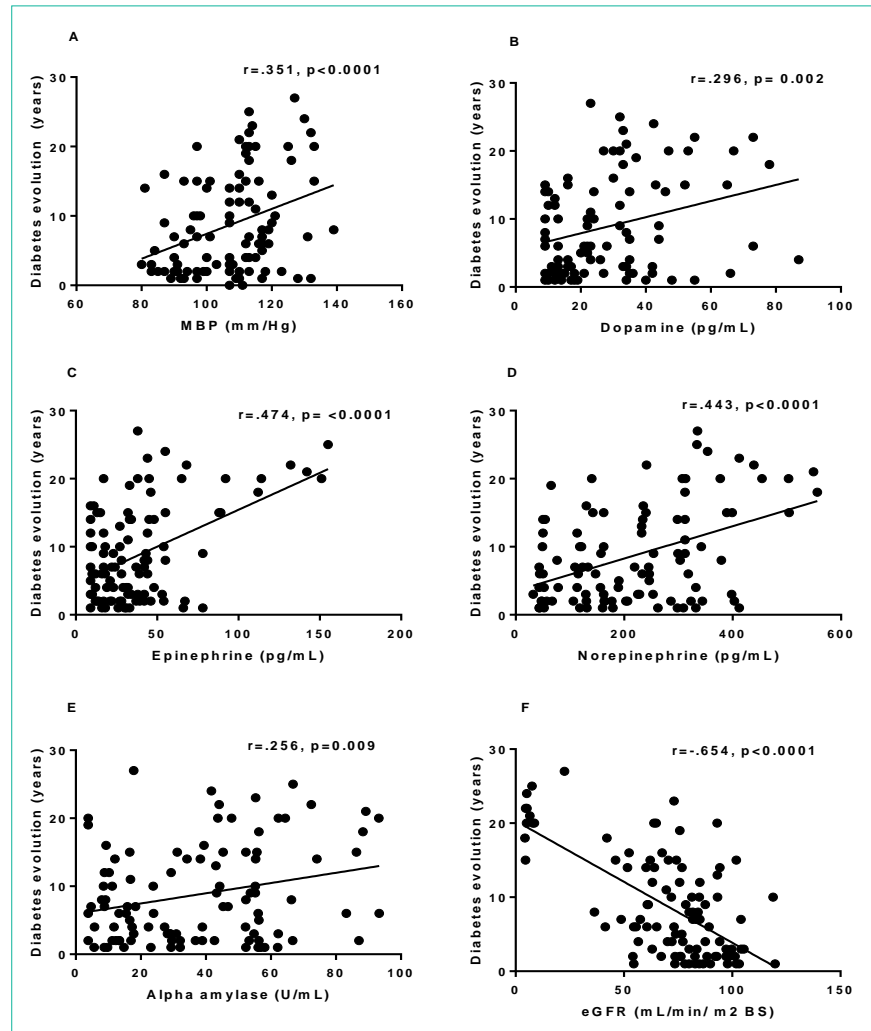

Figure 2: Correlation between diabetes evolution and A) Mean Blood Pressure (MBP); B) dopamine; C) Epinephrine; D) Norepinephrine; E) Salivary alpha Amylase; F) Estimated Glomerular Filtration Rate (eGFR).

We also found increase in serum renalase and salivary alpha amylase concentrations in SM and correlation between serum renalase, and salivary alpha amylase. Moreover, correlation between time since T2DM diagnosis, blood pressure, and plasma catecholamines, was found. These results interesting and support because MS has been considered as a SNS disease [42].

Here, we report that hyperactivity of SNS is present since early stages of metabolic alterations that precede clinical T2DM such as MS, hypertension and obesity, and this would justify the compensatory increase in serum renalase found in SM and T2DM patients, a term that describes this finding would be "resistance to renalase" though it has not been referred yet in world literature. Clearly, additional studies are needed to confirm or rule out this hypothesis. In this study, special care was taken to not including T2DM patients with clinical manifestations of diabetic dysautonomia and treated with beta-blockers.

Is evident the inexorable evolution that follows the natural history of T2DM in the development of chronic complications such as diabetic nephropathy. In this study we reported increase in serum concentrations of renalase and a reduction in eGFR in patients with MS and T2DM, so it can be inferred that kidneys are the main source of renalase, and its compensatory increase is due to SNS hyperactivity.

Finally, we found that renalase and alpha amylase have influence on T2DM and ESRD groups, additionally, a positive correlation between alpha amylase, plasma concentrations of catecholamines and diabetes evolution were found. These results suggests that

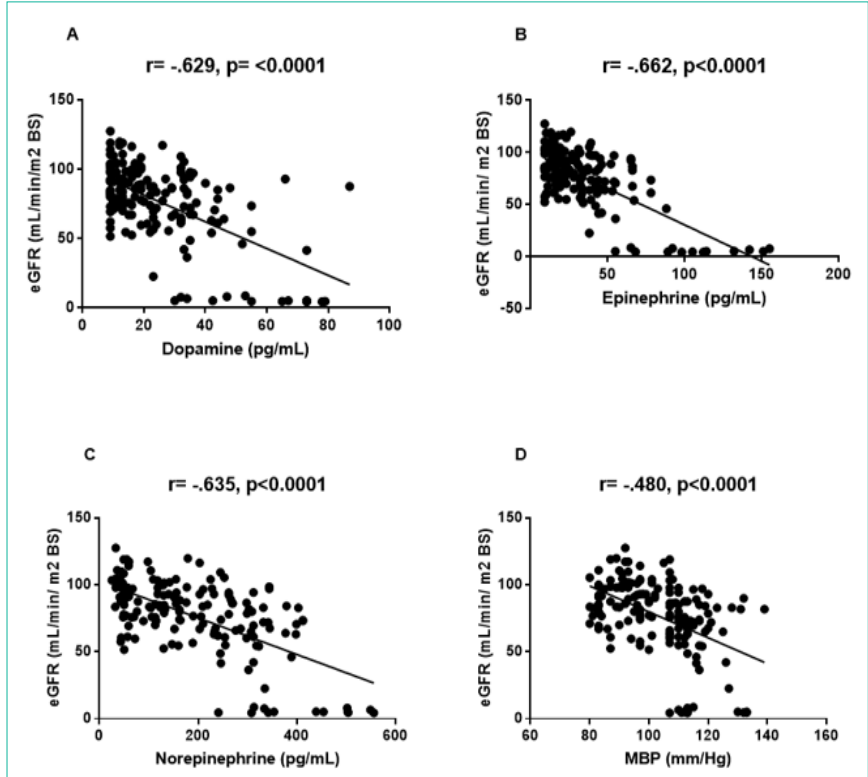

Figure 3: Correlations between Estimated Glomerular Filtration Rate (eGFR) and A) dopamine; B) epinephrine; C) norepinephrine; D) Mean Blood Pressure (MBP).

determination of salivary alpha amylaseas a marker of non-invasive sympathetic activity in T2DM and ESRD patients, results of clinical importance $[36,37]$.

Our study has some limitations, one of them is small number of subjects studied, so similar studies with a larger number of patients should be conducted. Another limitation is the failure to measure insulin sensitivity in patients with MS, although hypertension [43] and obesity [44] are considered states of insulin resistance. Another limitation is having determined only serum renalase concentrations and not urinary concentrations, since, as mentioned above, urinary renalase is up to 100 times more active than serum renalase [45], so this variable should be controlled in future studies.

In conclusion, sympathetic hyperactivity in MS, T2DM, and ESRD patients was founded. Serum renalase and salivary alpha amylase increased when eTFG diminishes and associate with plasmatic concentration of catecholamines. Renalase and salivary alpha amylase are proposed as biomarkers of renal function and sympathetic hyperactivity, respectively. Though additional studies are required to describe the pathophysiological mechanisms involved, these results highlight the importance of implementing preventive measures that diminishes risk factors forT2DM and preserve residual kidney function in patients with impaired kidney function.

\section{References}

1. Grundy SM, Cleeman JI, Daniels SR, Donato KA, Eckel RH, Franklin BA, et al. Diagnosis and management of metabolic syndrome: an American Heart Association/National Heart Lung and Blood Institute scientific statement. Circulation. 2005; 112: 2735-2752.

2. Eckel RH, Grundy SM, Zimmet PZ. The metabolic syndrome. Lancet. 2005; 365: 1415-1428.

3. Zimmet PZ, Alberti KG, Shaw JE. Mainstreaming the metabolic syndrome: a definitive definition. Editorial. Med J Aust. 2005; 183: 175-176.

4. American Diabetes Association. Standards of Medical Care in Diabetes 2015 Summary of Revisions. Diabetes Care. 2015; 38: S1-S93. 
5. Juutilainen A, Lehto S, Rönnemaa T, Piörälä K, Laakso M. Type 2 diabetes as a "Coronary Heart Disease Equivalent". Diabetes Care. 2005; 28: 2901 2907.

6. National Kidney Foundation. K/DOQI Clinical Practice Guidelines for Chronic Kidney Diseases: evaluation, classification and stratification. Am J Kidney Dis. 2002; 39: S1-S266.

7. National Institute of Diabetes and Digestive and Kidney Diseases. United States Renal Data System 2012 Annual Data Report: Atlas of End-Stage Renal Disease in the United States. Washington, D.C.: U.S. Government Printing Office. 2012: 2

8. United States Renal Data System. USRDS 2007 Annual Data Report. Bethesda, MD: National Institute of Diabetes and Digestive and Kidney Diseases, National Institutes of Health, U.S. Department of Health and Human Services. 2007

9. KDIGO Clinical Practice Guideline for the Evaluation and Management of Chronic Kidney Disease. Kidney Int Suppl. 2013; 3: 1-150.

10. Xu J, Li G, Wang P, Velazquez H, Yao X, Li Y. Renalase is a novel, soluble monoamine oxidase that regulates cardiac function and blood pressure. J Clin Inv. 2005; 115: 1275-1280.

11. Li G, Xu J, Wang P, Velazquez H, Li Y, Wu Y, et al. Catecholamines regulate the activity, secretion, and synthesis of renalase. Circulation. 2008; 117 1277-1282.

12. Desir GV. Regulation of blood pressure and cardiovascular function by renalase. Kidney Int. 2009; 76: 366-370.

13. Desir GV, Peixoto AJ. Renalase in hypertension and kidney disease. Nephrol Dial Trasplant. 2014; 29: 22-28.

14. Rampersaud E, Damcott CM, Fu M, Shen $\mathrm{H}$, Mc Ardle $\mathrm{P}$, Shi X, et al. Identification of novel candidate genes for type 2 diabetes from a genomewide association scan in the old older Amish: evidence for replication from diabetes-related quantitative traits and from independent populations. Diabetes. 2007; 56: 3053-3062.

15. Yin J, Lu Z, Wang F, Jiang Z, Lu L, Miao N, et al. Renalase attenuates hypertension, renal injury and cardiac remodeling in rats with subtota nephrectomy. J Cell Mol Med. 2016; 20: 1106-1117.

16. Ramasubbu N, Paloth V, Luo Y, Brayer GD, Levine MJ. Structure of ora cavity. Acta Crystallographic Section D Biological Crystallography. 1996: 52 435-446.

17. Stegeren AV, Rohleder N, Everaerd W, Wolf OT. Salivary alpha amylase as marker for adrenergic activity during stress: effect of betablockade. Psychoneuroendocrinology. 2006; 31: 137-142.

18. Vineetha R, Pai KM, Vengal M, Gopalakrishna K, Narayakurup D. Usefulness of salivary alpha amylase as a biomarker of chronic stress and stress related oral mucosal changes-a pilot study. J ClinExp Dent. 2014; 6: e132-e137.

19. Zbroch E, Malyszko J, Koc-Zorawska E, Mysliwiec M. Renalase, kidney function, and markers of endothelial dysfunction in renal transplant recipients. Pol Arch Med Wewn. 2012; 122: 40-44.

20. Gaber EW, El-Attar HA. The relationship between dopamine and renalase in type 2 diabetic patients with and without diabetic nephropathy. British J DiabVasc Dis. 2013; 13: 3130-3137

21. American Diabetes Association. Diagnosis and Classification of Diabetes Mellitus. 2014; 34: S81-S90.

22. Zimmet AP, Shaw J. Metabolic syndrome-a new world-wide definition. A Consensus Statement from the International Diabetes Federation. Diab Met. 2006; 23: 469-480.

23. Montañéz-Bermudez J, Bover-Sanuán J, Oliver-Samper A, Ballarin-Castán JA, Gracia-Garcia S. Valoración de la nueva ecuación CKD-EPI para la estimación del filtrado glomerular. Nefrología. 2010; 30: 185-194.

24. Krum H, Lambert E, Windebank E, Campbell DJ, Esler M. Effect of angiotensin II receptor blockade on autonomic nervous system function in patients with essential hypertension. Am J Physiol Heart Circ Physiol. 2006; 290: H1706-H1712.
25. Davy KP, Orr JS. Sympathetic nervous system behavior in human obesity Neurocience Biobehavioral Reviews. 2009; 33: 116-124.

26. Mancia G, Bousquet P, Elghozi JL, Esler M, Grassi G, Julius S, et al. The sympathetic nervous system and the metabolic syndrome. J Hypertens. 2007; 25: 909-920

27. Kobayashi D, Takamura M, Murai H, Usui S, Ikeda T, et al. Effect of pioglitazone on muscle sympathetic nerve activity in type 2 diabetes mellitus with $\alpha$-glucosidase inhibitor. AutonNeurosci. 2010; 158: 86-91.

28. Muoio DM, Newgard CB. Mechanisms of disease: molecular and metabolic mechanisms of insulin resistance and $\beta$-cell failure in type 2 diabetes. Nat Rev Mol Cell Biol. 2008; 9: 193-205.

29. Schwartz MW, Woods SC, Porte D, Seeley RJ, Baskin DG. Central nervous system control of food intake. Nature. 2000; 404: 661-671.

30. Luft FC. Renalase, a catecholamine-metabolizing hormone from the kidney. Cell Metabolism. 2005; 1: 358-360.

31. Chatterton RT, Vogelsong KM, Lu Yu-cai, Ellman AB, Hudgens GA. Salivary a-amylase as a measure of endogenous adrenergic activity. Clin Physiol. 1996; 16: 433-448

32. Nater UM, Rohleder N. Salivary alpha-amylase as a non-invasive biomarker for the sympathetic nervous system: Current state of research. Psyconeuroendocrinology. 2009; 34: 486-496.

33. Grassi G, Seravalle G, Dell'Oro R, Turri C, Bolla GB, Mancia G. Adrenergic and reflex abnormalities in obesity-related hypertension. Hypertension. 2000 36: $538-542$.

34. Corry DB, Tuck ML. Obesity, hypertension and sympathetic nervous system activity. Current hypertension Reports. 1999; 1: 119-126.

35. Huggett RJ, Scott EM, Gilbey SG, Stoker JB, Mackintosh AF, Mary DASG. et al. Impact of type 2 diabetes mellitus on sympathetic neural mechanism in hypertension. Circulation. 2003; 108: 3097-3101.

36. Neuman J, Ligtenberg G, Klein II, Koomans HA, Blankestijn PJ. Sympathetic hyperactivity in chronic kidney disease: pathogenesis, clinical relevance, and treatment. Kidney Int 2004; 65: 1568-1576.

37. Chrapko B, Grzebalska A, Nocun A, Ksiazek K, Andrzej D. Cardiac sympathetic hyperactivity in chronic kidney disease. A comparison between haemodialysis and peritoneal dialysis patients. Nuclear Medicine Review. 2014; 17: 75-82.

38. Sarnak MJ, Levey AS, Schoolwerth AC, Coresh J, Culleton B, Hamm JJ, et al. Kidney disease as a risk factor for development of cardiovascular disease. Circulation. 2003; 108: 2154-2169.

39. Zbroch E, Malyszko J, Malyszko JS, Koc-Zorawska E, Mysliwiec M Renalase, a novel enzyme involved in blood pressure regulation, is related to kidney function but not to blood pressure in hemodialysis patients. Kidney Blood Press Res. 2012; 35: 395-399.

40. Acharya V, Olivero J. The kidney as an endocrine organ. Methodist Debakey Cardiovasc J. 2018; 14: 305-307.

41. Gorodezky C, Alaez C, Vazquez-García MN, D La Rasa G, Infante E, Balladares S, et al. The genetic structure of Mexican Mestizos of different locations: tracking back their origins through MHC genes, blood group systems, and microsatellites. Hum Immunol. 2001; 62: 979-981.

42. Schlaich M, Straznicky N, Lambert E, Lambert G. Metabolic syndrome: a sympathetic disease? Lancet diabetes and endocrinol. 2015; 3: 148-157.

43. Ferrannini E, Haffner SM, Stern MP. Essential hypertension: an insulinresistant state. J Cardiovasc Pharmacol. 1990; 15: S18-S25.

44. Ye J. Mechanisms of insulin resistance in obesity.Front Med. 2013; 7: 14-24.

45. Li G, Xu J, Wang P, Velazquez H, Li Y, Wu Y, et al. Catecholamines regulate the activity, secretion, and synthesis of renalase. Circulation. 2008; 117 : $1277-1282$ 